\title{
In memoriam Hans Sautter
}

Am 7. September 1984 ist Professor Dr. med. Dr. med. h.c. Hans Sautter im Alter von 72 Jahren gestorben. Sein Tod bedeutet auch für die Ophthalmologie einen uner-setzlichen Verlust.

Hans Sautter wurde am 6. April 1912 ge-boren. Seine Fachausbildung erfolgte an der Universitäts-Augenklinik Tubingen. Bereits 1940 habilitierte er sich, 1947 wurde er zum ausserplanmässigen Professor ernannt. 1953 erfolgte seine Berufung auf den Lehrstuhl für Augenheilkunde an der Hamburger Univer-sität. Einen Ruf nach Heidelberg 1958 und nach München 1965 lehnte er ab, weil ihn der Neubau der Hamburger Universitäts-Augenklinik als Lebensaufgabe faszinierte. Diese Klinik wurde entscheidend von ihm geplant und trotz vieler Schwierigkeiten als eine der weltweit modernsten realisiert, wo-bei ihm seine besondere Gabe durchdachter Organisation zugute kam.

Nach seiner Emeritierung 1981 zog sich Hans Sautter nach Savognin zurück, das er seit langem liebte. Die majestätische Umge-bung des Dorfes in Graubünden entsprach seinen sportlichen Ambitionen ebenso, wie es ihm Spielraum für weitere Arbeit liess.

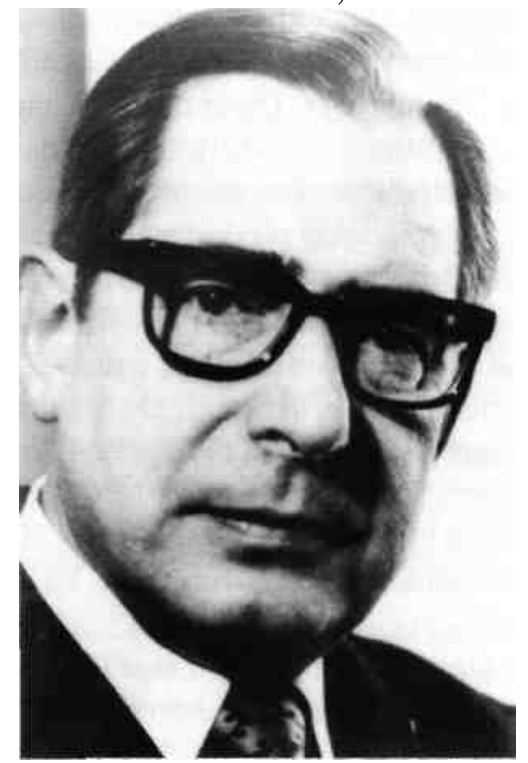

Hans Sautter begeisterte bereits seine Studenten - darunter auch den Schreiber dieser Zeilen durch eine von hohem Pflichtgefíihl geprägte, didaktisch hervorra-gende Vorlesung. Diesen Eindruck vermit-telte er gleichermassen auf Kongressen mit seinem brillanten Vortrag und seinen ge-

66

In memoriam Hans Sautter

schliffenen Diskussionen. Aufgrund der kla-ren Diktion, seines reichen Wortschatzes und des eindringlichen, fundierten Inhalts waren die Vorträge Hans Sautters nicht nur für den Hörer ein 
künstlerischer Genuss, sondern darüber hinaus oft Höhepunkte na-tionaler und internationaler Tagungen.

Äussere Ehrungen wurden Hans Sautter reichlich zuteil: Hier seien lediglich seine Wahl zum Dekan der Medizinischen Fakul-tät derUniversität Hamburg, seine Mitglied-schaft im Internationalen Ophthalmologen-rat, seine Wahl in die Academia Ophthal-mologica Internationalis, die Promotion zum Dr. med. h. c. sowie seine Zugehörigkeit zur Deutschen Akademie der Naturforscher und Ärzte Leopoldina genannt.

Hans Sautter war Ehrenmitglied einer Reihe von nationalen und internationalen Fachgesellschaften. Er gehörte mehrere Jahre lang dem Vorstand der Deutschen Ophthalmologischen Gesellschaft an, 2 Jahre lang war er ihr erster Vorsitzender. Während dieses Präsidialamtes wurde 1966 in München der Internationale Ophthalmo-logenkongress abgehalten. 1976 prägte Hans Sautter den Europäischen Ophthalmolo-genkongress in Hamburg, eine in jeder Hin-sicht von hohem Niveau getragene Veran-staltung.

Hans Sautter war in erster Linie Kliniker. Zahlreiche Publikationen haben, breit gefá-chert, unser Fach zum Gegenstand und fan-den ihren Niederschlag auch in einer Reihe von Publikationen des Karger-Verlags, dem er besonders verbunden war: Er war lange Jahre Editor der «Advances in Ophthalmo-logy» sowie, bis zu seinem Tode, Editor von «Ophthalmologica». Neben experimentel-len und klinischen Fragen der Durchblu-tungsstörungen, insbesondere am Augenhintergrund - hier haben seine Veröffentlichungen über arteriosklerotische Erkran-kungen der Netzhautmitte besonderes Ge-wicht befassen sich seine weiteren Arbei-ten hauptsächlich mit Problemen der Kera-toplastik, des Glaukoms sowie der Starope-ration. Eine von ihm mitentwickelte Mikro-chirurgieeinrichtung zeugt von einer auch in den späteren Jahren seiner Hamburger Tä-tigkeit immer dem echten Fortschritt zuge-wandten Einstellung. Sein Buch über die Morphologie der Linsentrübungen bleibt ein Standardwerk, darüber hinaus hat er zwei Atlanten über Erkrankungen des Augenhintergrundes veröffentlicht. Die Publikationen von Hans Sautter haben einen we-sentlichen und nachhaltigen Anteil an der augenärztlichen Weiterbildung unserer Generation. Er hat viele neue Akzente gesetzt. Die Schule von Hans Sautter besteht weiter: Drei seiner Schüler sind Lehrstuhlinhaber, acht weitere Chefärzte von Augenkliniken bzw. Augenabteilungen. Zahlreiche nieder-gelassene ehemalige Assistenten verdanken ihm ihre praxisnahe, solide Fachausbil-dung. Auch nach seiner Emeritierung stand Hans Sautter seinen Schülern und Freunden stets und uneingeschränkt zur Verfügung. Sein weiser Rat wird uns in Zukunft fehlen. Die immer selbstverständliche Autorität entsprach bei aller fachlicher Distanz dem Verhältnis zu seinen Mitarbeitern und Patienten, denen er aufgeschlossen, mit Wärme und Fürsorge entgegentrat. Ihn prägte auch die Offenheit in der Begegnung sowie seine fröhliche Geselligkeit und Gastfreundschaft.

D. Durch einen tragischen Unfall ist Hans Sautter als einer der Grossen unseres Faches von uns gegangen. Wir werden ihn nicht ver-gessen.

Wolfgang Straub 